DEMOGRAPHIC RESEARCH

VOLUME 34, ARTICLE 38, PAGES 1063-1074

PUBLISHED 22 JUNE 2016

http://www.demographic-research.org/Volumes/Vol34/38/

DOI: $\quad$ 10.4054/DemRes.2016.34.38

Descriptive Finding

Convergence in male and female life expectancy: Direction, age pattern, and causes

\title{
Benjamin Seligman
}

Gabi Greenberg

Shripad Tuljapurkar

(c) 2016 Seligman, Greenberg \& Tuljapurkar.

This open-access work is published under the terms of the Creative Commons Attribution NonCommercial License 2.0 Germany, which permits use, reproduction \& distribution in any medium for non-commercial purposes, provided the original author(s) and source are given credit. See http://creativecommons.org/licenses/by-nc/2.0/de/ 


\section{Table of Contents}

$1 \quad$ Introduction $\quad 1064$

1.1 The Lee-Carter model 1064

1.2 Trends in mortality 1065

2 Methods 1066

$3 \quad$ Results 1066

4 Discussion $\quad 1072$

$\begin{array}{ll}\text { References } & 1073\end{array}$ 


\title{
Convergence in male and female life expectancy: Direction, age pattern, and causes
}

\author{
Benjamin Seligman ${ }^{1,3}$ \\ Gabi Greenberg ${ }^{2}$ \\ Shripad Tuljapurkar ${ }^{3}$
}

\begin{abstract}
BACKGROUND

The cornerstone of mortality- and life-expectancy forecasting in developed nations, the Lee-Carter model relies on assumptions of there being a dominant singular value that captures most of the variance within a matrix of age-specific mortality rates over time and that the time trend captured by this lead singular value is constant. We revisit the model's predictive ability and trends in mortality decline among developed nations since the end of the Cold War.
\end{abstract}

\section{OBJECTIVE}

To understand the predictive power of the Lee-Carter model with mortality trends since 1990.

\section{METHODS}

Mortality data were obtained from the Human Mortality Database. Forecasts were made using $\mathrm{R}$ with random walk forecasts using the package forecast.

\section{RESULTS}

While Lee-Carter forecasts of life expectancy for combined sexes were accurate, sexspecific forecasts tended to somewhat overestimate for females and significantly underestimate for males. Further investigation of the trend for males shows that the first singular value continues to capture the majority of the variation in mortality since 1990, with progress along this dimension moving at a constant rate.

\footnotetext{
1 Stanford University, School of Medicine. U.S.A. E-Mail:bensel@gmail.com.

2 Stanford University, Department of Statistics. U.S.A.

3 Stanford University, Department of Biology. U.S.A.
} 


\section{CONCLUSIONS}

Lee-Carter forecasts have significantly underestimated gains in male life expectancy without major changes to the model's assumptions. We believe this represents more rapid progress in tackling male mortality in the $\mathrm{G} 7$ countries without major changes to the age pattern of these gains. Curiously, this has not affected combined-sex forecasts, potentially being offset by slight overestimation of female mortality progress.

\section{CONTRIBUTION}

We show that the Lee-Carter model has made inaccurate forecasts of mortality rates unrelated to violations of its underlying assumptions.

\section{Introduction}

The Lee-Carter method has become the standard approach for forecasting mortality and life expectancy of human populations, particularly among developed countries. In addition to representing a significant advance in forecasting methods when it was developed, its findings with respect to historical mortality trends are of significant substantive interest. Some twenty years after its initial development and widespread adoption among actuarial agencies, we revisit the model's predictive capability and the trends in mortality decline in the developed world since the end of the Cold War.

\subsection{The Lee-Carter model}

In the Lee-Carter model (Lee and Carter 1992; Lee 1999), the log of mortality at age $\mathrm{x}$ in year $\mathrm{t}$ is represented in this form:

$$
\log \left(m_{x, t}\right)=a_{x}+b_{x} * k_{t}
$$

where $a_{x}$ is a vector of average, across a given base set of years, log mortality rates by age, $b_{x}$ is a vector that can be seen as representing the 'slope' of log mortality rates by age over time, and $k_{t}$ is a vector with each element representing the 'level of mortality' in a given year, which is explained further below.

The key methodological innovation behind this model was the application of singular value decomposition to a centered matrix of log age-specific mortality rates by year. One may think of this as a principal-components analysis of this matrix. Typically, the first principal component captures $\geq 85 \%$ of the variance. The loadings onto the first principal component, usually normalized to sum to one, form the vector $b$, while the scores, which would then be normalized to sum to zero, are the $k$ s. Higher-order components could, in principle, be used; however, none of them accounts for a substantial amount of the 
residual after the first principal component is accounted for. During the $20^{\text {th }}$ century, the $k s$ have been roughly linear over time in most developed countries (Tuljapurkar, $\mathrm{Li}$, and Boe 2000). As $a$ and $b$ are constant over time, a random walk with drift to forecast the $k \mathrm{~s}$ can in turn forecast mortality rates and life expectancy with meaningful prediction intervals. This is also of substantive interest as the forces that would produce a linear relationship over time - as opposed to a discontinuous form as new innovations emerge, or a flattening curve as improvements in mortality diminish - remain unclear.

Extensions to this model have been made since its initial publication, allowing for coherent forecasts of subpopulations ( $\mathrm{Li}$ and Lee 2005; Hyndman, Booth, and Yasmeen 2013) and attempting to allow for changing age-specific responses to the main time trend (Li and Gerland 2012; Li, Lee, and Gerland 2013). However, the fundamental underpinnings of the model have remained, namely 1) that there is a dominant single time trend that explains the overwhelming majority of the variation in mortality rates over time and 2) that this dominant time trend is linear. We investigate whether these assumptions still hold and discuss the implications for forecasts.

\subsection{Trends in mortality}

Over the past century, there has been dramatic change in mortality rates and life expectancy in developed countries. In the United States, for example, estimated life expectancy rose from 47.3 years in 1900 to 76.8 in 2008. The causes of death, likewise, have changed from being largely infectious diseases to noncommunicable, usually chronic diseases (Armstrong, Conn, and Pinner 1999), in line with the ideas of the epidemiologic transition (Omran 1971; Olshansky and Ault 1986). This theory offers a framework for how causes of death change in populations that are also undergoing a demographic transition: initially, life expectancy is in the 20 s to 30 s, with deaths primarily from hunger, epidemic disease, and perinatal causes. As societies develop economically, mortality rates from these causes gradually decline, and life expectancy rises into the 40s or 50s. Finally, chronic diseases such as cancer and cardiovascular disease dominate the causes of death, although mortality rates continue to decline. At this point life expectancy is often in the $60 \mathrm{~s}$ or $70 \mathrm{~s}$. A fourth stage of so-called delayed degenerative diseases has also been proposed, as mortality from chronic diseases is pushed back to ever older ages (Olshansky and Ault 1986).

Under this model, increases in life expectancy lead to the emergence of diseases that are progressively harder to treat and, with onset later in life, lead to less gain in life expectancy when treated successfully. This would predict that improvements in mortality will gradually slow and the previously described linear trend in a single dominant time signal may give way to nonlinear trends or multiple relevant time signals. Thus, we 
also explore the Lee-Carter model's forecasts with actual trends in mortality since its inception.

The other major trend in mortality in developed countries has been the convergence of life expectancy between the sexes. Since the early 1970s the gap between male and female life expectancy, which had been widening, has narrowed. We assess what this has done to forecasts of life expectancy for combined and separate sexes.

\section{Methods}

Life tables and population size by age and sex for the G7 countries (Canada, France, Germany, Italy, Japan, the United Kingdom, and the United States) were taken from the Human Mortality Database (HMD) (University of California, Berkeley and Max Planck Institute for Demographic Research no year). The analysis of Germany was limited to the regions that comprised the former West Germany, while national populations for the UK and France were used out of the available options. Forecasts were made from 1990 to 2010 for each sex separately and both sexes combined, with the Lee-Carter model fit using data beginning in 1950 (1956 for West Germany) and ending in 1989.

To construct survival probabilities and life expectancies, mortality in the first year of life was estimated using formulae for males, females, and both sexes combined as appropriate (Preston, Keyfitz, and Schoen 1972; Preston, Heuveline, and Guillot 2001).

To explore the extent to which other principal components capture mortality trends, the orthogonal complement was calculated as a measure of the residual to the Lee-Carter fitted $\log$ mortality rates as the difference of the two vectors of mortality rates.

Analysis was conducted using $\mathrm{R}$ version 2.15.2 in the RStudio IDE version 0.97 with forecasting run using the forecast package (R Core Team 2012; Hyndman and Khandakar 2008; RStudio 2012).

\section{Results}

Figures 1-3 show the forecast results for combined sexes, males, and females. Overall, the observed trends in life expectancy remain linear over the period studied. Forecasts using different base years do not differ substantially, although those using first and second stage $k$ s differ somewhat in the magnitude of difference between forecast and observed life expectancy (but not in the direction of the difference). Notably, for the four European countries and Canada, mean forecast life expectancy is substantially lower than what is observed, with the difference increasing over time. This is particularly striking for Italy, Germany, and the UK. In the United States, forecasts are approximately congruent with 
observations.

\section{Figure 1: Lee-Carter life expectancy forecasts, combined sexes}
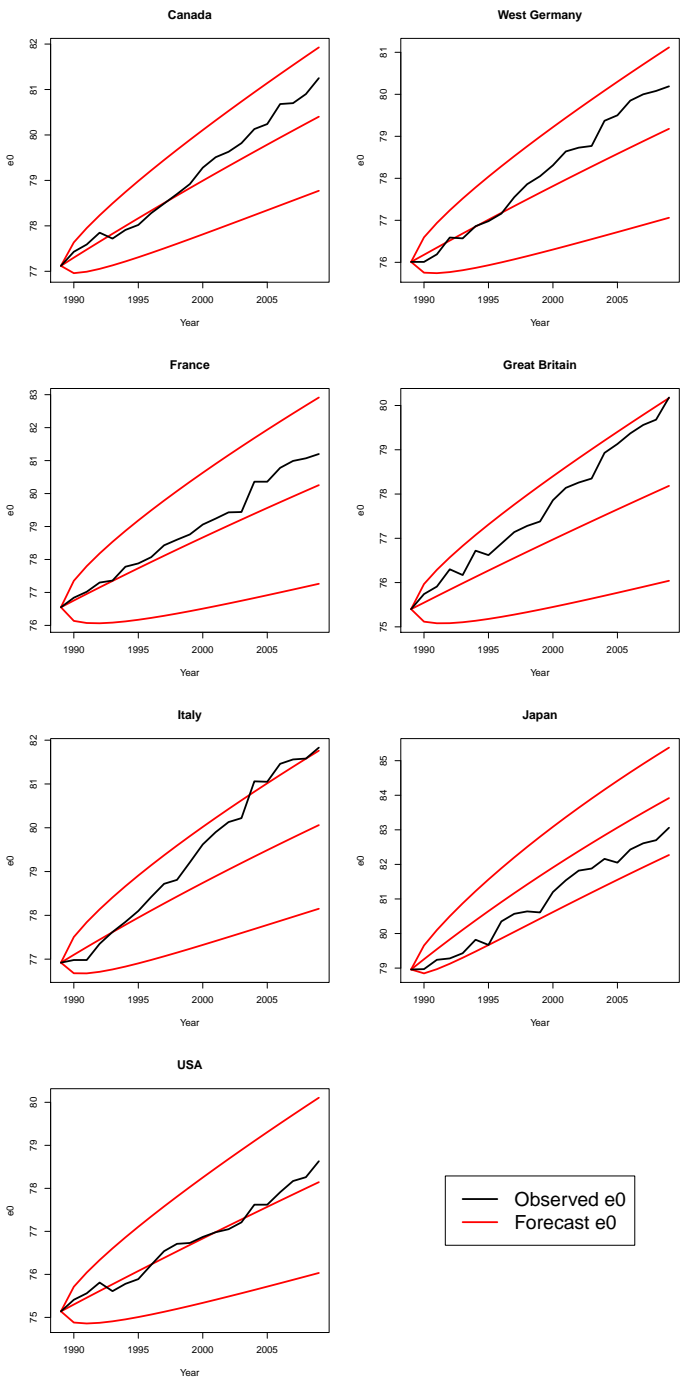

- Observed e0
- Forecast e0 
Seligman, Greenberg \& Tuljapurkar: Convergence in male and female life expectancy

Figure 2: $\quad$ Lee-Carter life expectancy forecasts, males
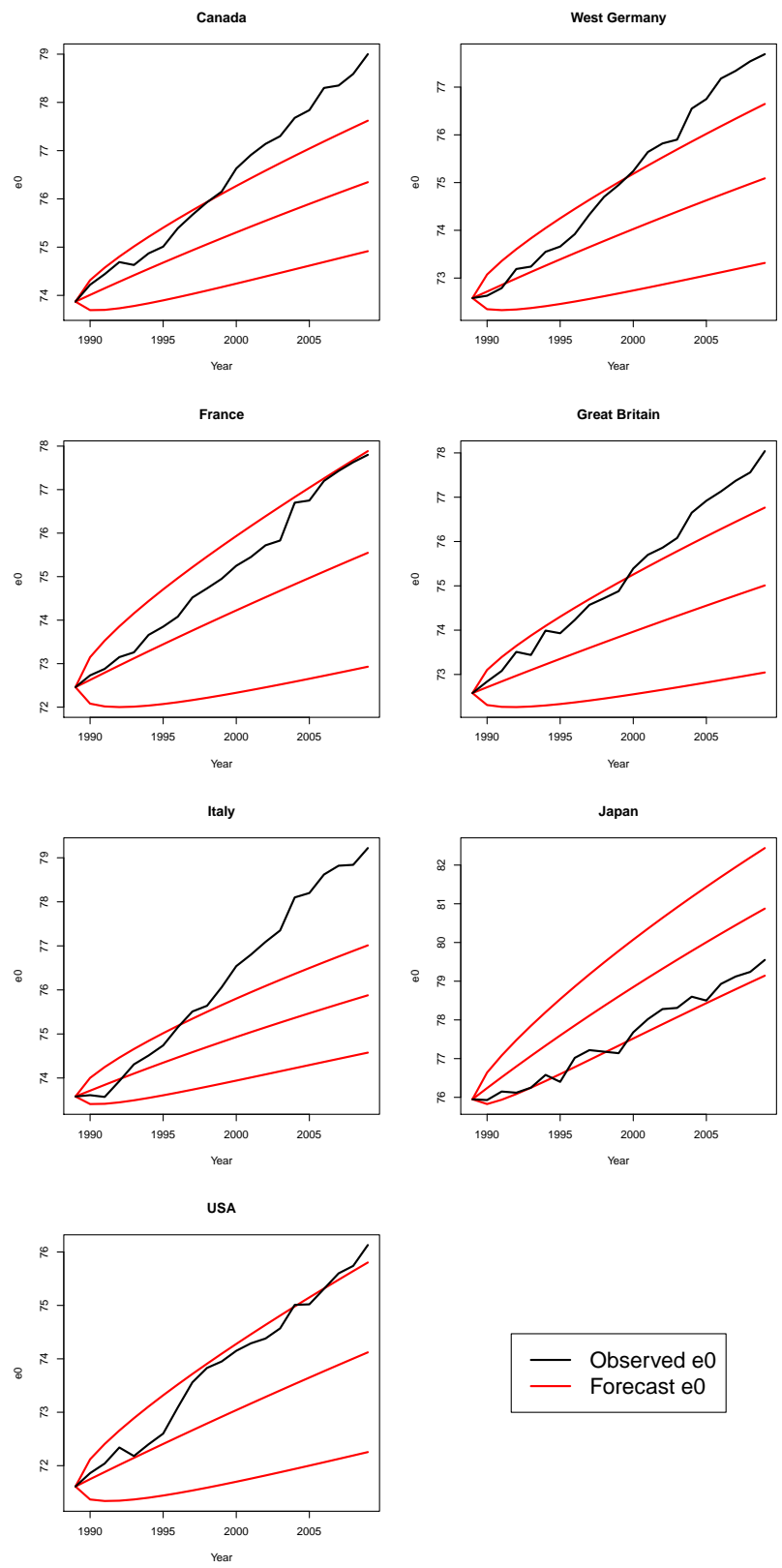
Figure 3: $\quad$ Lee-Carter life expectancy forecasts, females
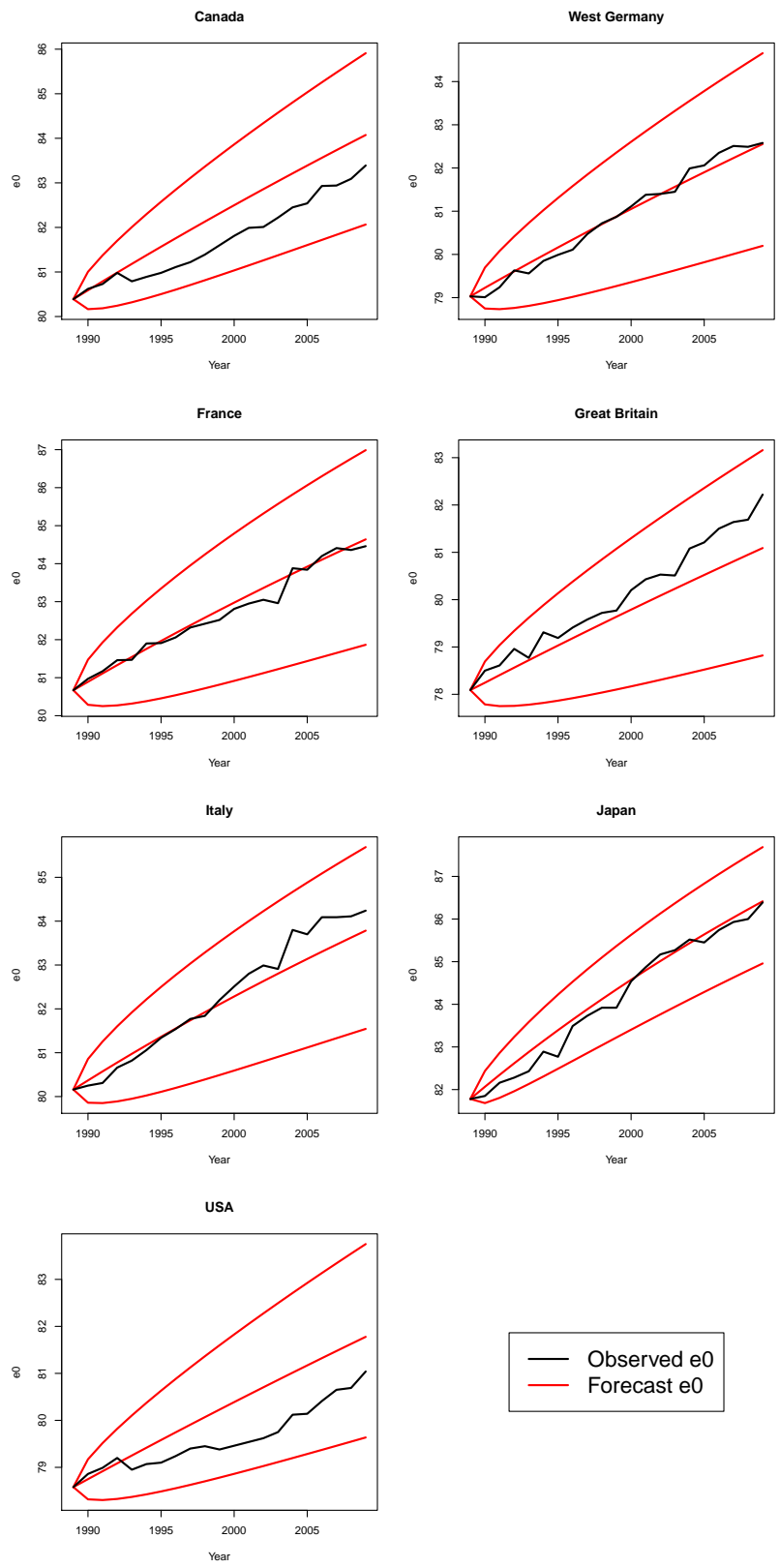

Observed e0 Forecast e0 
Among the results for females, most observed life expectancies were consistent with or somewhat above forecasts. The notable exceptions were the US and Canada, where observed life expectancy for women remained below forecasts throughout the period considered. For men in Canada, France, Germany, Italy, the UK, and the US, observed life expectancy rose faster than was forecast, crossing the 95\% forecast bound made with firststage $k s$ in all cases except France. Coherent forecasts made using the Lee-Li method did not improve forecasts of male mortality.

Japan stands out as the exception to this overall pattern. For Japan, the median forecasts are consistently optimistic compared to observed life expectancy for each sex, although observed trends remain within the $95 \%$ prediction interval. This indicates a deceleration in mortality improvement for both sexes in Japan. Importantly, Japan underwent a significant epidemiologic transition and experienced exceptionally rapid mortality decline during the baseline years. The slower decline in recent years is likely the result of convergence with other industrialized countries. However, unlike the other countries studied here, there is no male-female convergence in life expectancy.

Figure 4 shows the projection of logged mortality rates for males onto the first principal component and its orthogonal complement. The latter measures other time trends. Although the orthogonal complement increases over time in most countries, the bulk of the trend is captured by the first principal component. 
Figure 4: $\quad$ First principal component and orthogonal complement, males
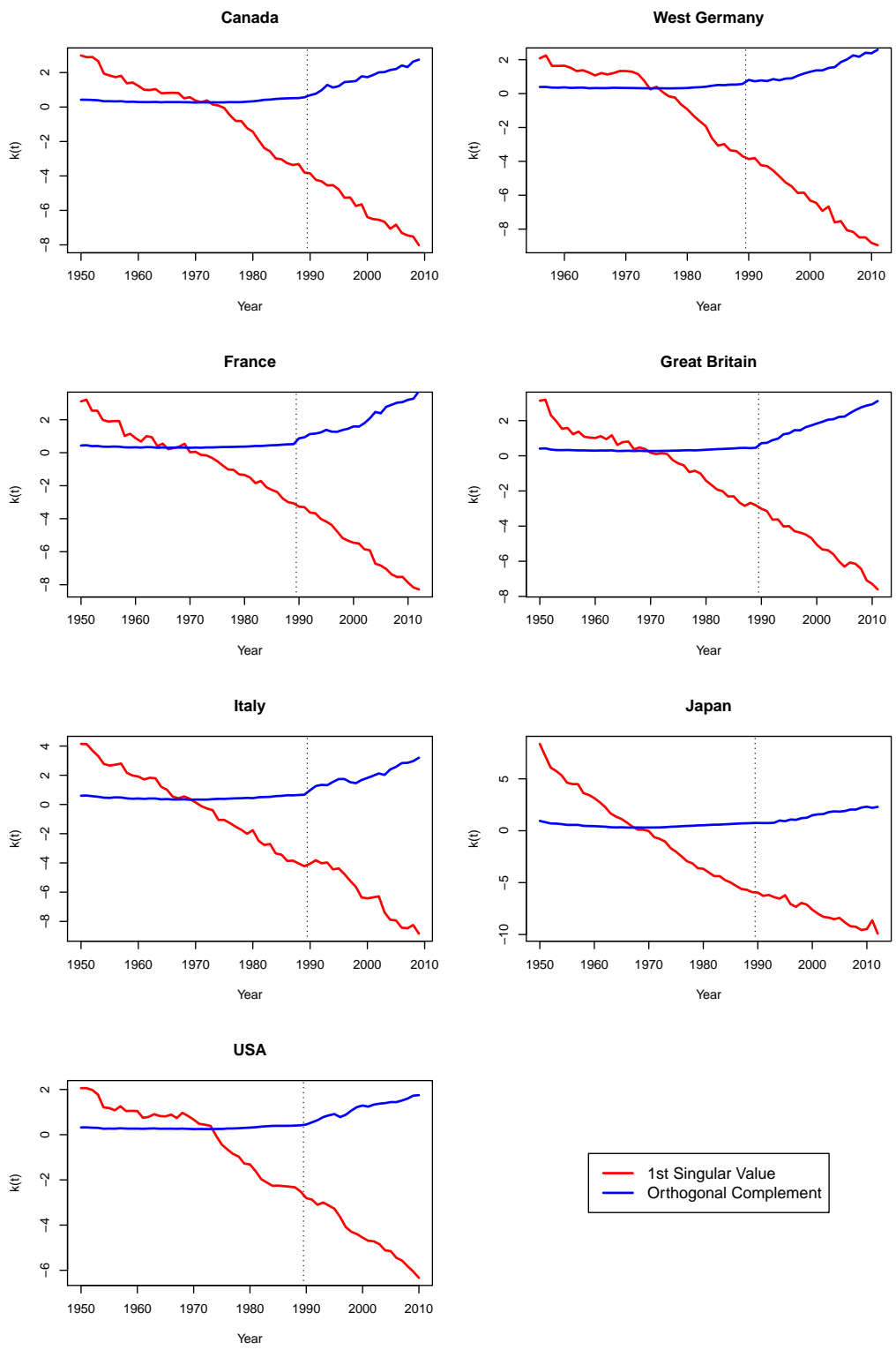


\section{Discussion}

The observed trends in life expectancy since 1990 show that life expectancy in the developed world continues to rise in a monotonic, linear fashion, suggesting that the underlying structure of mortality decline has not changed. Further, this rise in life expectancy does not appear to have slowed compared to the historic trend as captured by the forecasts. We also find that male life expectancy has risen more rapidly than would be predicted using the standard Lee-Carter model, a feature that has been noted by others investigating the decline in the male-female difference in mortality (Wang and Preston 2009; Technical Panel on Assumptions and Methods 2011). The changes we observe in the separate-sex models cannot be explained by incorporating higher singular values into the model. The cause of the divergence between forecast and observed male life expectancy is uncertain. However, the cardiovascular revolution that began in the late 1960s is certainly part of the story. In general, CVD mortality among men has declined at a rate faster than in women (Roger et al. 2010; Parikh et al. 2009; Levi 2002). This lends itself to two hypotheses:

1. Improvements in the treatment of CVD and its risk factors since the $1980 \mathrm{~s}-$ including use of ACE inhibitors, beta blockers, and statins - as well as advances in the care of myocardial infarction have generally benefitted men more than women. There has been some evidence for differential benefit, primarily in terms of utilization of new technologies in women versus men (Vaccarino et al. 2005; GouniBerthold et al. 2008).

2. Changes in health behavior, particularly tobacco use, has have occured more rapidly and dramatically among men than women and account, for this differential. This has recent support from work incorporating tobacco use into Lee-Carter forecasting (Preston and Wang 2006).

It is also notable that, while forecasts have diverged substantially from observed life expectancy for males, they remain within prediction limits for combined sexes. While the evidence presented is not conclusive, it suggests that sex-composition effects may explain this particular observation. 


\section{References}

Armstrong, G.L., Conn, L.A., and Pinner, R.W. (1999). Trends in infectious disease mortality in the United States during the 20th century. Journal of the American Medical Association 281(1): 61-66. doi:10.1001/jama.281.1.61. http://www.ncbi.nlm.nih.gov/pubmed/9892452.

Gouni-Berthold, I., Berthold, H.K., Mantzoros, C.S., Böhm, M., and Krone, W. (2008). Sex disparities in the treatment and control of cardiovascular risk factors in type 2 diabetes. Diabetes Care 31(7): 1389-1391. doi:10.2337/dc08-0194.

Hyndman, R.J., Booth, H., and Yasmeen, F. (2013). Coherent mortality forecasting: The product-ratio method with functional time series models. Demography 50(1): 261283. doi:10.1007/s13524-012-0145-5.

Hyndman, R.J. and Khandakar, Y. (2008). Automatic time series forecasting: The forecast package for R. Journal of Statistical Software 27(3): 1-22. doi:10.18637/jss.v027.i03.

Lee, R. (1999). The Lee-Carter method for forecasting mortality, with various extensions and applications. North American Actuarial Journal 4(1): 80-93. doi:10.1080/10920277.2000.10595882.

Lee, R.D. and Carter, L.R. (1992). Modeling and forecasting U.S. mortality. Journal of the American Statistical Association 87(419): 659-671. doi:10.2307/2290204.

Levi, F. (2002). Trends in mortality from cardiovascular and cerebrovascular diseases in Europe and other areas of the world. Heart 88(2): 119-124. doi:10.1136/heart.88.2.119.

Li, N. and Gerland, P. (2012). Modifying the Lee-Carter method to project mortality changes up to 2100. Paper presented at the Population Association of America.

Li, N., Lee, R., and Gerland, P. (2013). Extending the Lee-Carter method to model the rotation of age patterns of mortality decline for long-term projections. Demography 50(6): 2037-2051. doi:10.1007/s13524-013-0232-2.

Li, N. and Lee, R.D. (2005). Coherent mortality forecasts for a group of populations: An extension of the Lee-Carter method. Demography 42(3): 575-594. doi:10.1353/dem.2005.0021.

Olshansky, S.J. and Ault, A.B. (1986). The fourth stage of the epidemiologic transition: The age of delayed degenerative diseases. The Milbank Quarterly 64(3): 355-391. doi:10.2307/3350025. http://www.ncbi.nlm.nih.gov/pubmed/3762504.

Omran, A.R. (1971). The epidemiologic transition: A theory of the epidemiology of 
population change. The Milbank Quarterly 49(4): 509-38. doi:10.2307/3349375.

Parikh, N.I., Gona, P., Larson, M.G., Fox, C.S., Benjamin, E.J., Murabito, J.M., O'Donnell, C.J., Vasan, R.S., and Levy, D. (2009). Long-term trends in myocardial infarction incidence and case fatality in the National Heart, Lung, and Blood Institute's Framingham Heart study. Circulation 119(9): 1203-1210. doi:10.1161/CIRCULATIONAHA.108.825364.

Preston, S., Heuveline, P., and Guillot, M. (2001). Demography: Measuring and modeling population processes. Hoboken: Wiley.

Preston, S.H., Keyfitz, N., and Schoen, R. (1972). Causes of death: life tables for national population. Napier: Seminar Press.

Preston, S.H. and Wang, H. (2006). Sex mortality differences in the United States: The role of cohort smoking patterns. Demography 43(4): 631-646. doi:10.1353/dem.2006.0037.

R Core Team (2012). R: A language and environment for statistical computing. Vienna: R Foundation for Statistical Computing. http://www.r-project.org/.

Roger, V.L., Weston, S.A., Gerber, Y., Killian, J.M., Dunlay, S.M., Jaffe, A.S., Bell, M.R., Kors, J., Yawn, B.P., and Jacobsen, S.J. (2010). Trends in incidence, severity, and outcome of hospitalized myocardial infarction. Circulation 121(7): 863-869. doi:10.1161/CIRCULATIONAHA.109.897249.

RStudio (2012). RStudio : Integrated development environment for R. http://www.rstudio.org/.

Technical Panel on Assumptions and Methods (2011). Report to the Social Security Advisory Board. Tech. rep., Social Security Advisory Board, Washington, D.C. http://www.ssab.gov/Reports/2011_TPAM_Final_Report.pdf.

Tuljapurkar, S., Li, N., and Boe, C. (2000). A universal pattern of mortality decline in the G7 countries. Nature 405(6788): 789-792. doi:10.1038/35015561.

University of California, Berkeley and Max Planck Institute for Demographic Research (no year). Human mortality database. www.mortality.org.

Vaccarino, V., Rathore, S.S., Wenger, N.K., Frederick, P.D., Abramson, J.L., Barron, H.V., Manhapra, A., Mallik, S., and Krumholz, H.M. (2005). Sex and racial differences in the management of acute myocardial infarction, 1994 through 2002. New England Journal of Medicine 353(7): 671-682. doi:10.1056/NEJMsa032214.

Wang, H. and Preston, S.H. (2009). Forecasting United States mortality using cohort smoking histories. Proceedings of the National Academy of Sciences of the United States of America 106(2): 393-398. doi:10.1073/pnas.0811809106. 